\title{
Smart Current Limitation Technique for a Multiphase Bearingless Machine with Combined Winding System
}

\author{
Zhuang Wen \\ Electrical and Electronic Engineering \\ The University of Nottingham \\ Nottingham, UK \\ zhuang.wen@nottingham.ac.uk
}

Luca Papini

Electrical and Electronic Engineering

The University of Nottingham

Nottingham, UK and Ningbo, China

Luca.Papini@nottingham.ac.uk

\author{
Giorgio Valente \\ Electrical and Electronic Engineering \\ The University of Nottingham \\ Nottingham, UK \\ giorgio.valente1@nottingham.ac.uk
}

Pericle Zanchetta

Electrical and Electronic Engineering

The University of Nottingham

Nottingham, UK

pericle.zanchetta@nottingham.ac.uk

\author{
Andrea Formentini \\ Electrical and Electronic Engineering \\ The University of Nottingham \\ Nottingham, UK \\ andrea.formentini@nottingham.ac.uk
}

\author{
Christopher Gerada \\ Electrical and Electronic Engineering \\ The University of Nottingham \\ Nottingham, UK and Ningbo, China \\ chris.gerada@nottingham.ac.uk
}

\begin{abstract}
This paper presents a current limitation technique for a multiphase bearingless machine featuring a combined winding system. This winding structure allows each machine phase to produce both suspension force and motoring torque. Compared to more conventional systems where two separate windings are adopted for the force and torque generation, the combined winding one leads to higher compactness and simpler manufacture. The main challenges with the combined winding configuration consist of decoupling the force and torque generation and designing a proper current limitation algorithm. The former topic has been already tackled and presented in previous publications, instead the latter will be addressed in this paper. In particular, the so called smart limitation technique will allow to prioritize either the suspension force or the torque generation. In this paper the priority is given to the rotor levitation, hence the suspension force rather than the torque is essential. The technique can be extended to give priority to the torque generation in further work and can be applied to any multiphase bearingless machine with similar winding structures. Finally, simulation results and experiment validation are provided.
\end{abstract}

Index Terms-Current limitation, Bearingless, Multiphase Machines, PM Synchronous Machines

\section{INTRODUCTION}

The lifetime and maintenance of electrical machines are often strongly affected by mechanical bearings. The rate of bearing failure is related to rotor vibrations caused by the eccentricity, the unbalance magnetic pull and other forces of different nature [1]. Furthermore, several industrial applications, especially chemical processes, require a perfect sterile environment. Therefore, mechanical bearings, which need lubricant to operate, would not be suitable as they would contaminate the substances [2], [3]. Bearingless machine, which are capable to generate levitation force and motoring torque in a single device, would overcome the aforementioned problems thanks to their contact-free operations. Furthermore, this technology would increase the operational speed of the machine beyond the limit of mechanical bearings leading to higher power density drives [4]-[6].

Conventional bearingless machines have two sets of independent windings, one responsible for the suspension force and the other one for the torque generation [7], [8]. The two windings have different current ratings, hence it is straightforward to determine the maximum achievable force and torque once the current to force and current to torque relationships for the suspension force and torque windings respectively are known. The two separate winding solution has the drawback of presenting an increased size due to the additional suspension force winding. Furthermore, it is still not a completely embedded solution. More recently, combined winding systems have been developed, mainly with multiphase winding arrangements. Several works can be found in the literature presenting different winding topologies and force and torque control techniques [7], [9], [10]. However, very little can be found regarding the current limitation issue. Indeed, when each machine phase produces both suspension force and torque it is not straightforward to determine the limits as they depend on the operating condition.

This paper presents a smart current limitation technique that can be applied to any multiphase machines with similar winding structures. The one installed in the considered bearingless machine consists of three three-phase windings, named sectors, hence the name Multi-Sector Permanent Magnet Synchronous Machine (MS-PMSM). Each sector is connected to an independent three-phase inverter. One machine sector occupies one third of the stator circumference and there is no overlapping between them [11]-[13]. Drive systems reliability requirements depend on the application, however, 


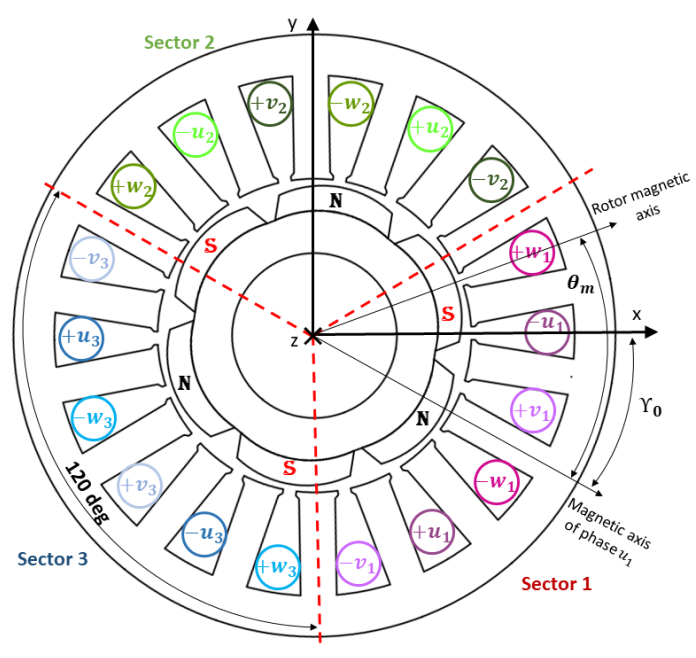

Fig. 1. Cross section of the machine.

for a bearingless machine, especially when operating at high speed, the shaft touch down could be fatal, hence it has to be avoided. Therefore, the limitation strategy has to prioritize the suspension force production. On the other hand, some industrial processes such as mixing of chemical substances where low speed bearingless motors are employed [2] may require to prioritize the torque generation accepting a potential shaft touchdown on the backup bearings. In this paper the smart limitation technique aims to guarantee the rotor suspension, at the expense of the torque generation. In a further work the technique will be extended considering the possibility of prioritizing the torque production.

In the next part, theory is presented. Then, the technique is verified with simulations in the Matlab-Simulink environment and with experimental tests.

\section{TheORETICAL InVESTIGATION}

\section{A. Force and torque generation}

Fig. 1 shows the crossing section of the bearingless MSPMSM considered in this work. This is a 18-slot-6-pole surface mount permanent magnet synchronous machine with newly designed winding. A three three-phase winding is installed in the stator. Each three-phase winding occupies one third of the stator, named sector. Each sector is supplied by an independent inverter to achieve independently suspension force and torque control. The structure and main dimensions of the machine are described more in detail in [11]-[13]. Furthermore, in the same paper the force and torque generation principles are described. Following the procedure presented in the aforementioned paper, the machine current reference vector $\bar{I}_{\alpha \beta}^{*}$ in the $\alpha-\beta$ reference frame can be computed as in (1) for each rotor electrical angular position $\vartheta_{e}$.

$$
\bar{I}_{\alpha \beta}^{*}=\mathbf{K}_{E}^{+}\left(\vartheta_{e}\right) \bar{W}^{*}
$$

$\bar{W}^{*}=\left[\begin{array}{lll}f_{x}^{*} & f_{y}^{*} & T^{*}\end{array}\right]^{T}$ is the wrench vector defined by piling the reference force components $f_{x}^{*}$ and $f_{y}^{*}$ and the reference torque $T^{*} \cdot \mathbf{K}_{E}^{+}\left(\vartheta_{e}\right)$ is the pseudo inverse of the electromagneto-mechanical coefficient matrix which describes the relationship between winding currents and the wrench vector. The considered MS-PMSM has three sectors, hence $\bar{I}_{\alpha \beta}^{*} \in$ $\mathbb{R}^{(6 \times 1)}$ and $\mathbf{K}_{E}^{+}\left(\vartheta_{e}\right) \in \mathbb{R}^{(6 \times 3)}$. The limitation technique aims to limit the machine phase current, therefore it is useful rewriting (2) in the phase current domain as follow:

$$
\bar{I}_{u v w}^{*}=\mathbf{K}_{u v w}^{+}\left(\vartheta_{e}\right) \bar{W}^{*}
$$

where

$$
\mathbf{K}_{u v w}^{+}\left(\vartheta_{e}\right)=\left[\begin{array}{ccc}
k_{u x 1}\left(\vartheta_{e}\right) & k_{u y 1}\left(\vartheta_{e}\right) & k_{u t 1}\left(\vartheta_{e}\right) \\
\vdots & \vdots & \vdots \\
k_{\# x s}\left(\vartheta_{e}\right) & k_{\# y s}\left(\vartheta_{e}\right) & k_{\# t s}\left(\vartheta_{e}\right) \\
\vdots & \vdots & \vdots \\
k_{w x 3}\left(\vartheta_{e}\right) & k_{w y 3}\left(\vartheta_{e}\right) & k_{w t 3}\left(\vartheta_{e}\right)
\end{array}\right]
$$

$\mathbf{K}_{u v w}^{+}\left(\vartheta_{e}\right)$ is obtained by applying (4). $k_{\# x s}\left(\vartheta_{e}\right), k_{\# y s}\left(\vartheta_{e}\right)$ and $k_{\# t s}\left(\vartheta_{e}\right)$ are the $x$-axis, $y$-axis force and torque coefficients respectively and \# stands for phase $u, v$ or $w$ and $s$ stands for sector 1,2 or 3.

$$
\mathbf{K}_{u v w}^{+}\left(\vartheta_{e}\right)=\mathbf{T}_{\mathbf{c}} \mathbf{K}_{E}^{+}\left(\vartheta_{e}\right)
$$

where $\mathbf{T}_{\mathbf{c}}$ is the nine-phase amplitude invariant ClarkeTransformation. The expression of the generic reference phase current is reported in

$$
i_{\# s}^{*}=k_{\# x s}\left(\vartheta_{e}\right) f_{x}^{*}+k_{\# y s}\left(\vartheta_{e}\right) f_{y}^{*}+k_{\# t s}\left(\vartheta_{e}\right) T^{*}
$$

It can be noticed that each machine reference phase current is made of two components: the first is related to the reference suspension force which can be represented by $\alpha_{\# s}\left(\vartheta_{e}, f_{x}^{*}, f_{y}^{*}\right)$ expressed in (6), the second to the reference torque $k_{\# t s}\left(\vartheta_{e}\right) T^{*}$ in (5).

$$
\alpha_{\# s}\left(\vartheta_{e}, f_{x}^{*}, f_{y}^{*}\right)=k_{\# x s}\left(\vartheta_{e}\right) f_{x}^{*}+k_{\# y s}\left(\vartheta_{e}\right) f_{y}^{*}
$$

In the next part the current limitation technique will be described.

\section{B. Current limitation technique}

Fig. 2 shows the block diagram of the control of the bearingless MS-PMSM. The reference force components $f_{x}^{*}$ and $f_{y}^{*}$, output of the position controllers are limited in the Suspension Force Limitation (SFL) block. Indeed, the following inequality has to be verified:

$$
\sqrt{\left(f_{x}^{*}\right)^{2}+\left(f_{y}^{*}\right)^{2}} \leq F_{\max }
$$

$F_{\max }$ is the maximum force magnitude that can be produced when $T^{*}=0 \mathrm{Nm}$. In the machine considered $F_{\max }=180 \mathrm{~N}$. Therefore, when the inequality (7) is true the outputs of the SFL block are $\bar{f}_{x}^{*}=f_{x}^{*}$ and $\bar{f}_{y}^{*}=f_{y}^{*}$, instead, when (7) is false the output are $\bar{f}_{x}^{*}=F_{\text {max }} \cos \theta_{f}$ and $\bar{f}_{y}^{*}=F_{\max } \sin \theta_{f}$, where $\theta_{f}$ is the suspension force direction.

The limited suspension force components $\bar{f}_{x}^{*}$ and $\bar{f}_{y}^{*}$ together with $\vartheta_{e}$ are the inputs of the Torque Limitation (TL) block 


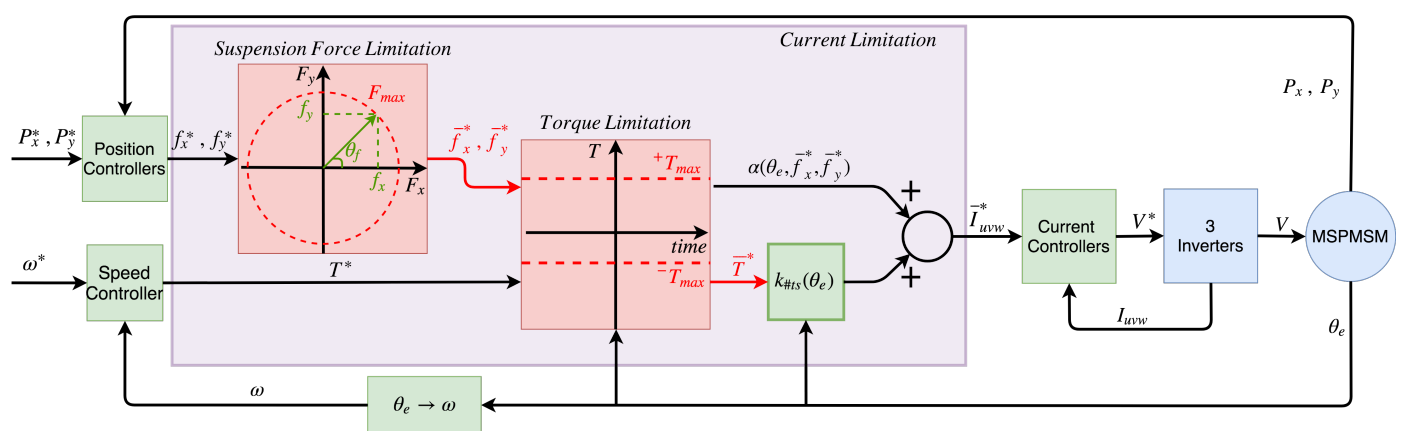

Fig. 2. Diagram of multi-sector permanent magnet synchronous motor levitation system.

in Fig. 2. The block calculates on-line the value of the maximum torque that the MS-PMSM can produce with the rated current $\left(I_{\text {rated }}=13 \mathrm{~A}\right)$ while generating at the same time the suspension force components $\bar{f}_{x}^{*}$ and $\bar{f}_{y}^{*}$. It should be noticed that maximum torque will change according to the suspension force required by the bearingless motor. Furthermore, a positive value ${ }^{+} T_{\max }$ and negative one ${ }^{-} T_{\max }$ have to be computed. The procedure can be summarized as follow. At first, for each machine phase $\alpha_{\# s}\left(\vartheta_{e}, f_{x}^{*}, f_{y}^{*}\right)$ is calculated as in (5) replacing $f_{x}^{*}$ and $f_{y}^{*}$ with $\bar{f}_{x}^{*}$ and $\bar{f}_{y}^{*}$. For the considered MS-PMSM nine values are obtained. Then, for each machine phase the maximum value of the positive and negative torque, ${ }^{+} T_{\# s}$ and ${ }^{-} T_{\# s}$, can be calculated in (8) and (9), respectively. Fig. 3 is the function image of (8) and (9). $\alpha_{\# s}\left(\vartheta_{e}, f_{x}^{*}, f_{y}^{*}\right)$ is the point of intersection of function image and $y$-axis. $k_{\# t s}\left(\vartheta_{e}\right)$ determines the slope of function image. The maximum positive and negative torque produced within rated current can be obtained by the points of intersection of function image and both of $\pm I_{\text {rated }}$ for each phase.

$$
\begin{aligned}
& { }^{+} T_{\# s}\left(\vartheta_{e}, \alpha_{\# s}\right)= \begin{cases}\frac{I_{\text {rated }}-\alpha_{\# s}}{k_{\# t s}\left(\vartheta_{e}\right)} & \text { if } k_{\# t s}\left(\vartheta_{e}\right)>0 \\
\frac{-I_{\text {rated }}-\alpha_{\# s}}{k_{\# t s}\left(\vartheta_{e}\right)} & \text { if } k_{\# t s}\left(\vartheta_{e}\right)<0\end{cases} \\
& { }^{-} T_{\# s}\left(\vartheta_{e}, \alpha_{\# s}\right)= \begin{cases}\frac{-I_{\text {rated }}-\alpha_{\# s}}{k_{\# t s}\left(\vartheta_{e}\right)} & \text { if } k_{\# t s}\left(\vartheta_{e}\right)>0 \\
\frac{I_{\text {rated }}-\alpha_{\# s}}{k_{\# t s}\left(\vartheta_{e}\right)} & \text { if } k_{\# t s}\left(\vartheta_{e}\right)<0\end{cases}
\end{aligned}
$$

In total nine values of ${ }^{+} T_{\# s}$ and of ${ }^{-} T_{\# s}$ have to be determined. Finally, ${ }^{+} T_{\max }$ and ${ }^{-} T_{\max }$ can be obtained in (10) and (11), respectively.

$$
\begin{array}{r}
{ }^{+} T_{\max }\left(\vartheta_{e}, \alpha_{\# s}\right)=\min \left({ }^{+} T_{u 1}\left(\vartheta_{e}, \alpha_{a 1}\right) \cdots\right. \\
\left.{ }^{+} T_{\# s}\left(\vartheta_{e}, \alpha_{\# s}\right) \cdots{ }^{+} T_{c 3}\left(\vartheta_{e}, \alpha_{w 3}\right)\right) \\
{ }^{-} T_{\max }\left(\vartheta_{e}, \alpha_{\# s}\right)=\max \left({ }^{-} T_{u 1}\left(\vartheta_{e}, \alpha_{a 1}\right) \cdots\right. \\
\left.{ }^{-} T_{\# s}\left(\vartheta_{e}, \alpha_{\# s}\right) \cdots{ }^{-} T_{w 3}\left(\vartheta_{e}, \alpha_{c 3}\right)\right)
\end{array}
$$

The torque $T^{*}$ output of the speed controller has to be limited in the TL block between ${ }^{-} T_{\max }\left(\vartheta_{e}, \alpha_{\# s}\right)$ and ${ }^{+} T_{\max }\left(\vartheta_{e}, \alpha_{\# s}\right)$. The outputs of the TL block are the nine $\alpha_{\# s}\left(\vartheta_{e}, \bar{f}_{x}^{*}, \bar{f}_{y}^{*}\right)$ and $\bar{T}^{*}$ that multiplies the gain $k_{\# t s}\left(\vartheta_{e}\right)$. The sum of $\alpha_{\# s}\left(\vartheta_{e}, \bar{f}_{x}^{*}, \bar{f}_{y}^{*}\right)$ and $k_{\# t s}\left(\vartheta_{e}\right) \bar{T}^{*}$ gives the limited phase reference current $i_{\# s}^{*}$. The limited reference current vector $\bar{I}_{u v w}^{*}$ is built piling the nine currents $\bar{i}_{\# s}^{*}$ and it is the
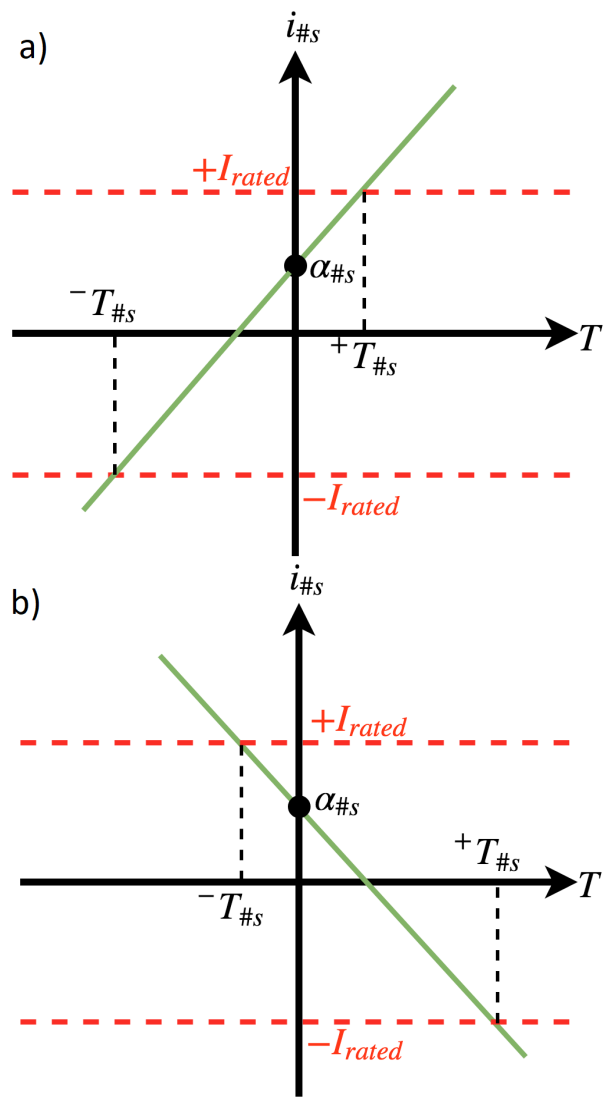

Fig. 3. Function image of Equation (8) and (9). a) $k_{\# t s}\left(\vartheta_{e}\right)>0$. b) $k_{\# t s}\left(\vartheta_{e}\right)<0$.

input to the current controller block that generates the voltage vector $\bar{V}^{*}$ to control the three three-phase inverters.

\section{Numerical Simulation Results}

The simulation model implemented in the Matlab-Simulink environment is represented by the block diagram in Fig. 2. The current loop and speed loop fit conventional PI controllers while a PID controller is applied in position loop. The machine considered has been designed to be overloaded for limited time, hence a maximum phase current of $20 \mathrm{~A}$ is chosen in the simulation. The values of rated current, maximum current during overload and maximum force during 

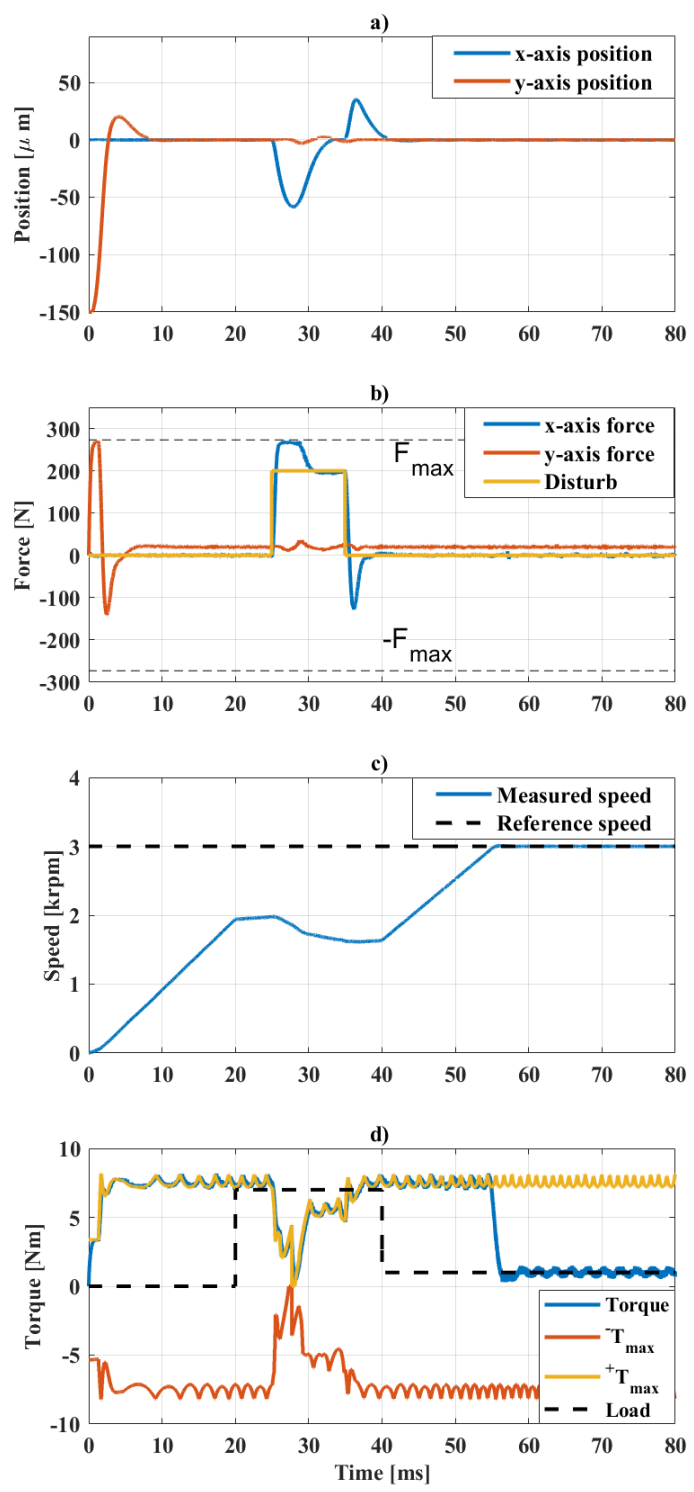

Fig. 4. Simulation results: a) $x-y$ axis rotor position; b) $x-y$ axis force components and force disturb; c)Rotor speed; d) Generated torque, load torque and torque limits

overload are listed in Table I.

TABLE I

\begin{tabular}{|c|c|}
\hline Parameter & Values \\
\hline Rated phase current $[A]$ & 13 \\
\hline Maximum phase current in Simulation $[A]$ & 20 \\
\hline Maximum allowed radial force in simulation $\left(F_{\max }\right)[N]$ & 273 \\
\hline
\end{tabular}

In the simulation, at first the rotor is brought from its resting position $\left[0 ;-\delta_{\max }\right]$, where $\delta_{\max }=150 \mu \mathrm{m}$ is the backup bearing clearance, to the centre of the stator $[0 ; 0]$. The transient lasts about $10 \mathrm{~ms}$ as can be observed in Fig. 4 a). During this time the maximum force $F_{\max }$ is applied on the $y$-axis in order to lift the rotor as can be appreciated from Fig. $4 \mathrm{~b}$ ). The speed reference $\omega^{*}=3 \mathrm{krpm}$ is commanded

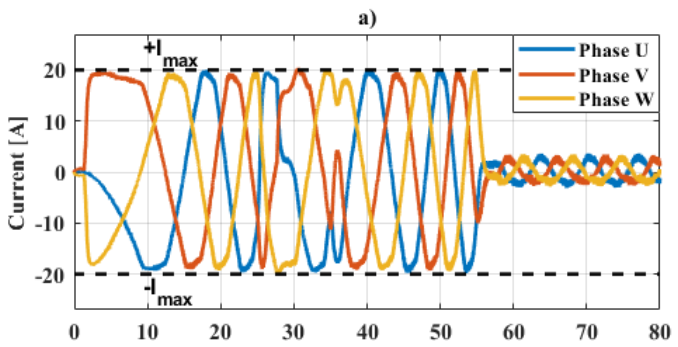

b)

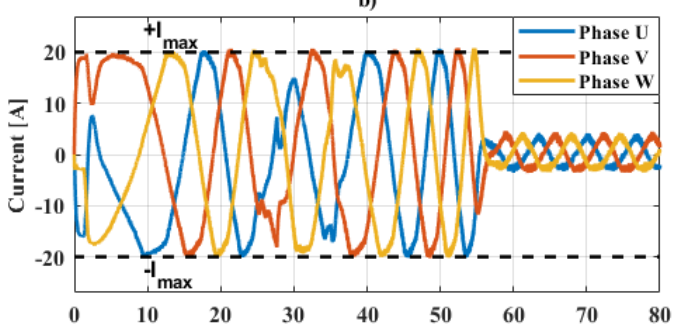

c)

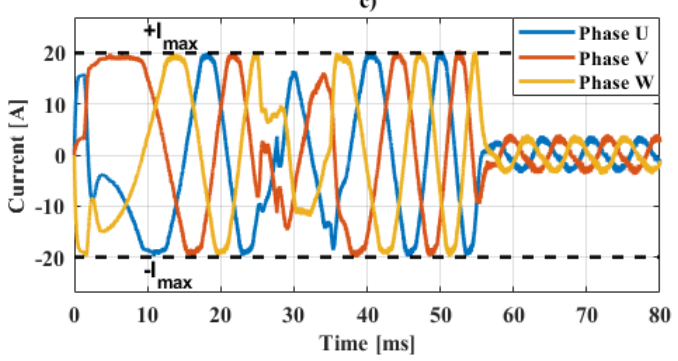

Fig. 5. Simulation results: a) Phase current of sector 1. b) Phase current of sector 2. c) Phase current of sector 3.

at the same time as shown Fig. 4 c). It can be noticed in Fig. 4 d) that during the position transient the available torque, given by ${ }^{-} T_{\max }$ and ${ }^{+} T_{\max }$, is remarkably reduced while the required levitation force is at its maximum. When the position transient is over the suspension force required is equal to the rotor weight force (about $20 \mathrm{~N}$ ), hence the torque available increases to almost its maximum value $8 \mathrm{Nm}$ so that the rotor can accelerate. During the speed transient a load of $7.5 \mathrm{Nm}$ is applied decreasing the rotor acceleration. Then, a force disturb of $200 \mathrm{~N}$ is applied on the $x$-axis. It can be observed that the motor can produce the suspension force required and maintain the rotor levitation with a short position perturbation at the expenses of the torque production. Indeed, the available torque is lower than the required one, hence the speed starts to decrease. The force disturb is removed at $35 \mathrm{~ms}$ and the load is reduced to $1 \mathrm{Nm}$ at $40 \mathrm{~ms}$ so that the rotor can accelerate again reaching the reference speed at around $60 \mathrm{~ms}$. Fig. 5 shows the simulation results of phase currents of three sectors. Phase currents never exceed the maximum value of $20 \mathrm{~A}$ while suspension forces are prioritized during all the simulation time. 


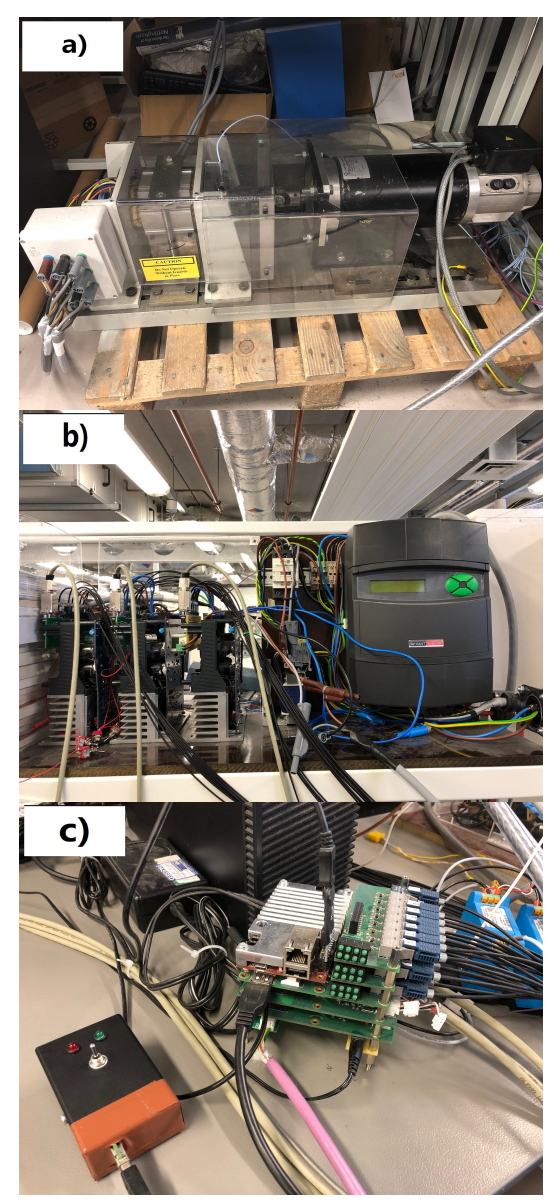

Fig. 6. Experimental rig: a) Bearingless MS-PMSM (left) and DC load (right); b) Three three-phase inverters (left) and DC servo drive (rigth); c) Control board (uCube).

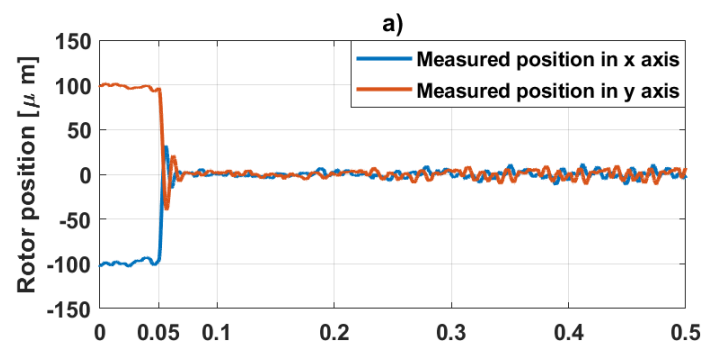

b)

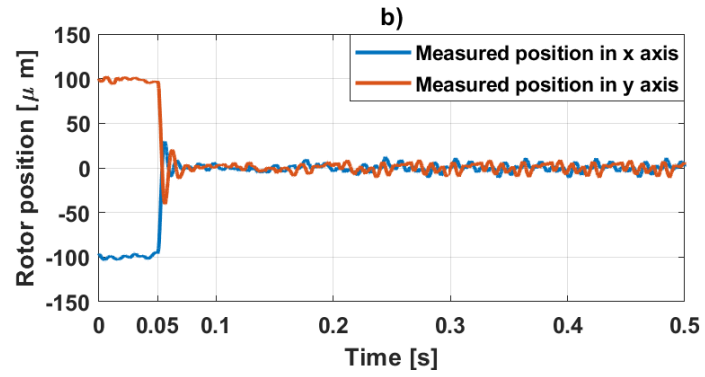

Fig. 7. Measured position of experimental tests: a)Without smart current limitation technique. b)With smart current limitation technique.

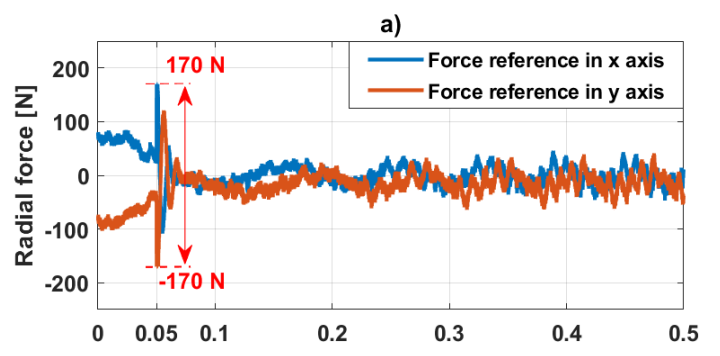

b)
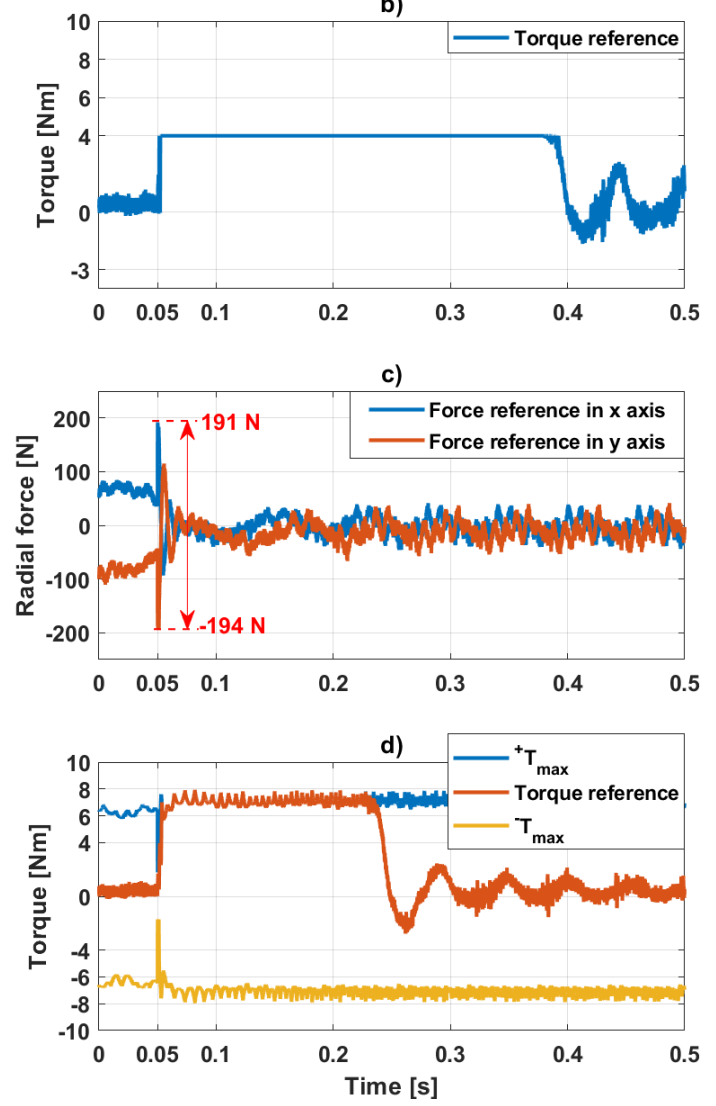

Fig. 8. Experimental results: a) Radial force references without smart current limitation technique. b) Torque reference without smart current limitation technique. c) Radial force references with smart current limitation technique. d) Torque reference with smart current limitation technique.

\section{EXPERIMENTAL VALIDATION}

The current limitation technique has been validated with a prototype bearingless MS-PMSM. The experimental results are displayed in this section.

Fig. 6 shows the experimental rig used for the validation. A DC permanent magnet motor is mechanically connected with the bearingless MS-PMSM machine through a universal joint (Fig. 6 a)). The three three-phase inverters that supply the MSPMSM and the DC servo drive that supplies the DC motor are shown in Fig. 6 b). Fig. 6 c) shows the custom made control platform ( $u C u b e)$ based on the off-the-shelf Microzed board from Avnet [14].

In this experimental validation the performance of the bearingless drive with and without the proposed smart saturation 


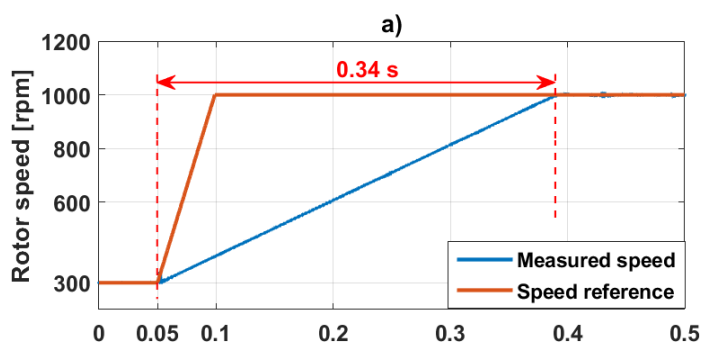

b)

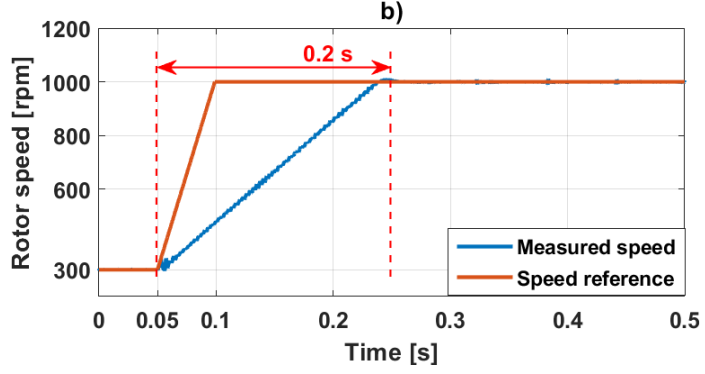

Fig. 9. Speed responses of experimental tests. a) The system without smart current limitation technique. b) The system with smart current limitation technique.
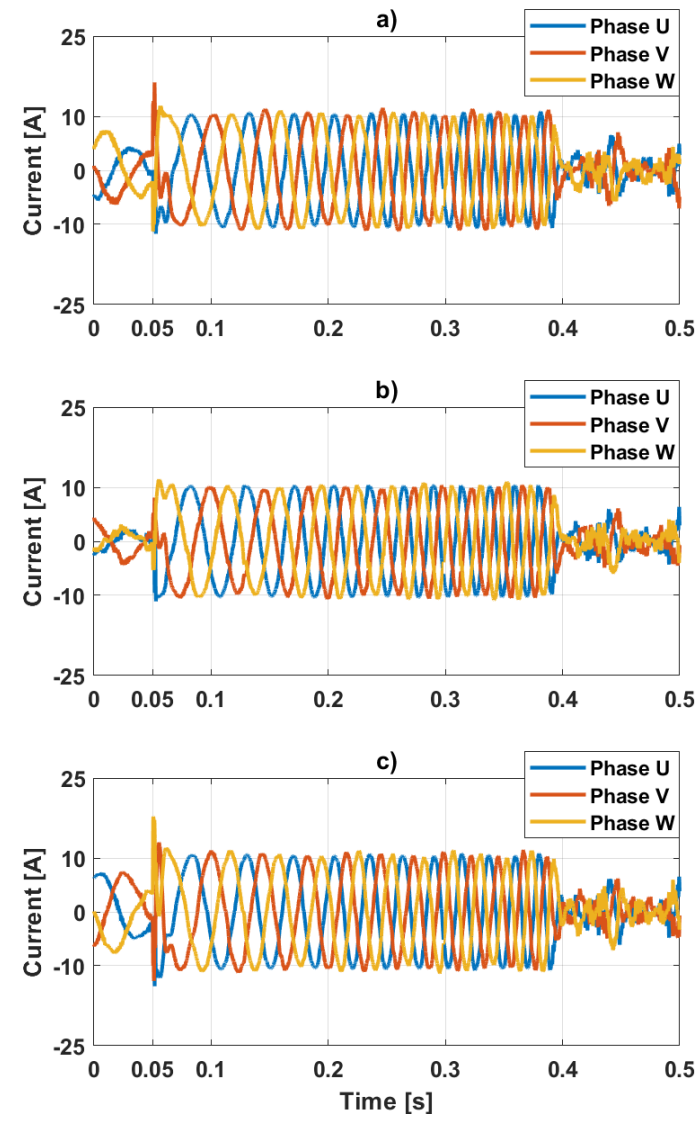

Fig. 10. Measured phase currents of experimental tests without smart current limitation technique: a) Sector 1. b) Sector 2. c) Sector 3.
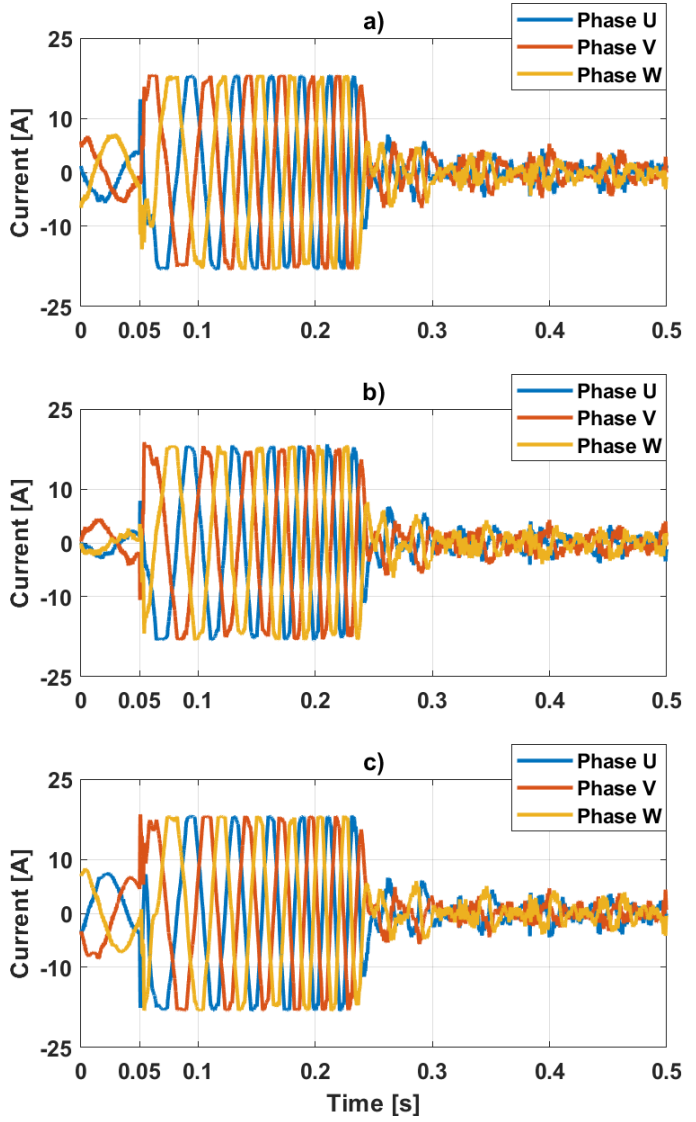

Fig. 11. Measured phase currents of experimental tests with smart current limitation technique: a) Sector 1. b) Sector 2. c) Sector 3.

technique will be presented. For the conventional system, without the smart saturation, the force and torque limits are fixed during operations. In order to satisfy the maximum machine current of $20 \mathrm{~A}$ the force and torque are limited to $240 \mathrm{~N}$ and $4 \mathrm{Nm}$, respectively. Indeed, these are the suspension force and motoring torque values that can be generated simultaneously without exceeding the machine ratings.

In the performed test, at first the rotor is lifted from its resting position $[-100 ; 100] \mu m$ to the centre of the stator $[0 ; 0]$ in $0.05 \mathrm{~s}$ for the conventional system (see in Fig. 7 a)) and the upgraded system (see Fig. 7 b)). During this time the maximum allowed suspension force is applied to the rotor: $240 \mathrm{~N}$ for the conventional system and $273 \mathrm{~N}$ for the upgraded system as shown in Fig. 8 a) and in Fig. 8 c), respectively. Fig. 8 b) shows that the output torque of the conventional system is $4 \mathrm{Nm}$ during the speed transient. On the other hand, it can be noticed from Fig. 8 c) and Fig. 8 d) that during the position transient the generated torque of the upgraded system is reduced while the required suspension force is at its maximum. When the position transient is over the suspension force required is significantly reduced so that the torque can increase to almost its maximum value $8 \mathrm{Nm}$. From Fig. 9 it can be found that the speed transient of the conventional system is longer than the one of the upgraded 
system because the maximum allowed torque of the upgraded system is bigger. Fig. 10 shows measured phase currents of the conventional system. The phase currents reach $20 \mathrm{~A}$ only at the time when both the maximum radial force and the maximum torque are required. In the upgraded system, phase currents reach $20 A$ during all the speed transient as shown in Fig. 11. It can be concluded that the system upgraded with the smart saturation technique allows to always exploit the full potential of the bearingless drive because it guarantees that the generated torque is always the maximum available.

\section{CONCLUSION}

A smart current limitation technique that prioritises the suspension force generation is presented and validated with numerical simulations and experimental tests. The algorithm has been applied to a bearingless MS-PMSM featuring a combined winding structure. The results show that the technique allows to maintain the rotor levitation and therefore avoid a potentially destructive touchdown at the expenses of the torque generation. Future work that has been identified as promising would consist of extending this technique to give priority to the torque production at the expense of the force.

\section{REFERENCES}

[1] C. Chamroon, M. O. T. Cole, and T. Wongratanaphisan, "An active vibration control strategy to prevent nonlinearly coupled rotor-stator whirl responses in multimode rotor-dynamic systems," IEEE Transactions on Control Systems Technology, vol. 22, no. 3, pp. 1122-1129, May 2014.

[2] K. Raggl, B. Warberger, T. Nussbaumer, S. Burger, and J. W. Kolar, "Robust angle-sensorless control of a pmsm bearingless pump," IEEE Transactions on Industrial Electronics, vol. 56, no. 6, pp. 2076-2085, June 2009.

[3] T. Zhang, X. Liu, L. Mo, X. Ye, W. Ni, W. Ding, J. Huang, and X. Wang, "Modeling and analysis of hybrid permanent magnet type bearingless motor," IEEE Transactions on Magnetics, vol. 54, no. 3, pp. 1-4, March 2018.

[4] X. Sun, L. Chen, and Z. Yang, "Overview of bearingless permanentmagnet synchronous motors," IEEE Transactions on Industrial Electronics, vol. 60, no. 12, pp. 5528-5538, Dec 2013.

[5] H. Jia, J. Wang, M. Cheng, W. Hua, and S. Fei, "Mathematical model of radial suspending force for a new stator-permanent magnet bearingless machine," IEEE Transactions on Magnetics, vol. 51, no. 11, pp. 1-4, Nov 2015

[6] X. Sun, L. Chen, and Z. Yang, "Overview of bearingless permanentmagnet synchronous motors," IEEE Transactions on Industrial Electronics, vol. 60, no. 12, pp. 5528-5538, Dec 2013.

[7] A. Chiba, T. Deido, T. Fukao, and M. A. Rahman, "An analysis of bearingless ac motors," IEEE Transactions on Energy Conversion, vol. 9 , no. 1, pp. 61-68, Mar 1994.

[8] K. Inagaki, A. Chiba, M. A. Rahman, and T. Fukao, "Performance characteristics of inset-type permanent magnet bearingless motor drives," in 2000 IEEE Power Engineering Society Winter Meeting. Conference Proceedings (Cat. No.00CH37077), vol. 1, Jan 2000, pp. 202-207 vol.1.

[9] W. K. S. Khoo, K. Kalita, and S. D. Garvey, "Practical implementation of the bridge configured winding for producing controllable transverse forces in electrical machines," IEEE Transactions on Magnetics, vol. 47, no. 6, pp. 1712-1718, June 2011.

[10] X. L. Wang, Q. C. Zhong, Z. Q. Deng, and S. Z. Yue, "Current-controlled multiphase slice permanent magnetic bearingless motors with opencircuited phases: Fault-tolerant controllability and its verification," IEEE Transactions on Industrial Electronics, vol. 59, no. 5, pp. 2059-2072, 2012.

[11] G. Valente, L. Papini, A. Formentini, C. Gerada, and P. Zanchetta, "Radial force control of multi-sector permanent magnet machines," in 2016 XXII International Conference on Electrical Machines (ICEM), Sep. 2016, pp. 2595-2601.
[12] G. Valente, A. Formentini, L. Papini, C. Gerada, and P. Zanchetta, "Performance improvement of bearingless multisector pmsm with optimal robust position control," IEEE Transactions on Power Electronics, vol. 34, no. 4, pp. 3575-3585, April 2019.

[13] G. Valente, L. Papini, A. Formentini, C. Gerada, and P. Zanchetta, "Radial force control of multisector permanent-magnet machines for vibration suppression," IEEE Transactions on Industrial Electronics, vol. 65 , no. 7, pp. 5395-5405, July 2018.

[14] A. Galassini, G. L. Calzo, A. Formentini, C. Gerada, P. Zanchetta, and A. Costabeber, "ucube: Control platform for power electronics," in 2017 IEEE Workshop on Electrical Machines Design, Control and Diagnosis (WEMDCD), April 2017, pp. 216-221. 